\title{
Reimagining the JMM with Your Help
}

\section{Jill Pipher and Catherine Roberts}

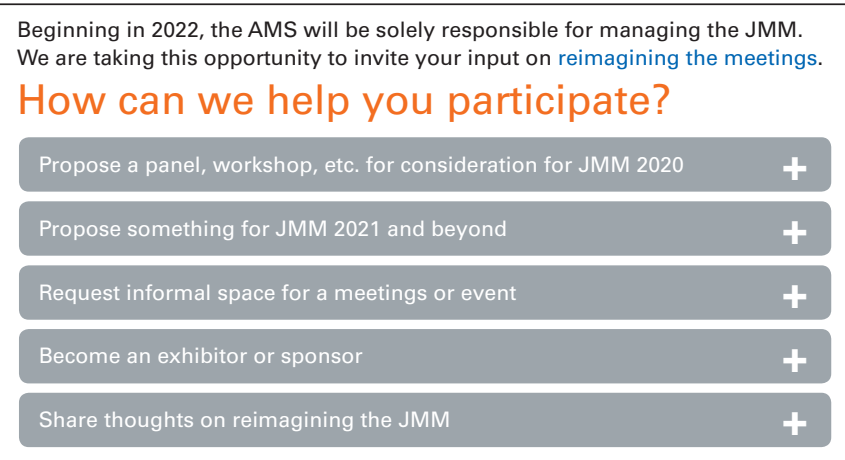

More than a year has passed since the announcement of upcoming changes to the Joint Mathematics Meetings (see November 2018 Notices). Starting with the January 2022 meetings in Seattle, the AMS will solely manage the JMM. Moreover, the Mathematical Association of America will be reducing the programming it currently organizes for the JMM. We are pleased to provide this update to help keep our community informed.

While there is still much to do as we prepare to take over management of the JMM in 2022, work is underway. This spring, the AMS Council and Board of Trustees endorsed the following statement to illustrate our commitment to ensuring these meetings remain relevant to our entire community:

The American Mathematical Society endorses the principle that the Joint Mathematics Meetings will strive to represent the full spectrum of interests of the mathematical community.

Jill Pipher is Elisha Benjamin Andrews Professor of Mathematics at Brown University and President of the American Mathematical Society. Her email address is Ji11_Pipher@Brown.edu.

Catherine Roberts is Executive Director of the AMS. Her email address is exdir@ams.org.

For permission to reprint this article, please contact: reprint-permission aams.org.

DOI: https://dx.doi.org/10.1090/noti2003
The new Joint Meetings Planning Committee (JMPC) is now at work. This ad hoc committee's principal activities are "to oversee the planning for and conduct of the annual January mathematics meetings, including the overall structure of the program, the overall schedule, and the inclusion of sessions and events sponsored by other organizations." Members are Secretary Carla D. Savage (Chair), Associate Secretaries Georgia Benkart and Steven H. Weintraub, Executive Director Catherine A. Roberts, Associate Executive Director T. Christine Stevens, and Director of Meetings Penny Pina. Our initial meetings this fall identified and classified what needs to happen and how we will proceed. The AMS is determining how to best incorporate programming from several other organizations into the JMM.

In the meantime, we have received hundreds of comments, suggestions, and offers from individuals and other mathematical societies. Much of this arrived via our JMM Reimagined portal, which continues to gather input and suggestions from our community at http://www. ams .org/about-us/jmm-reimagined This summer's MAA MathFest featured a Q\&A session with the executive directors from both the AMS and MAA. Hopefully, this session reassured those who value teaching-related sessions and

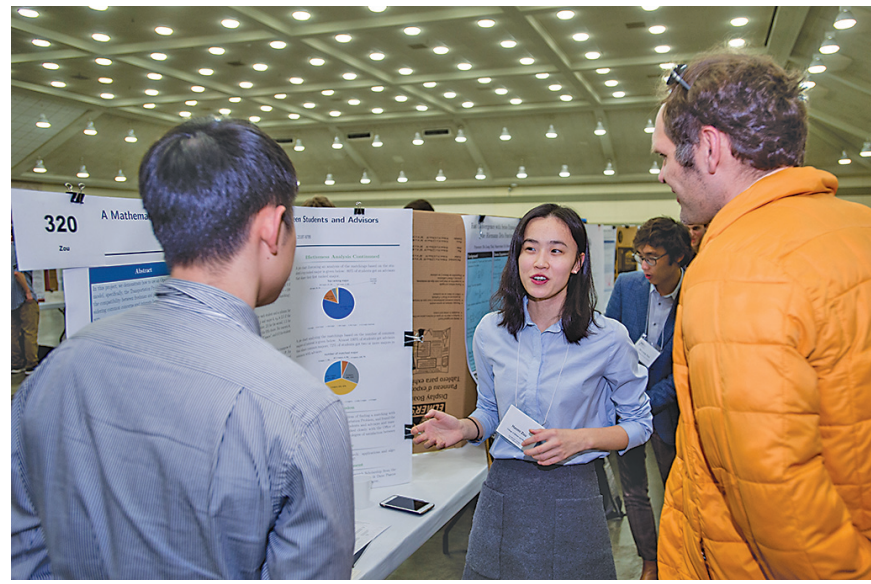




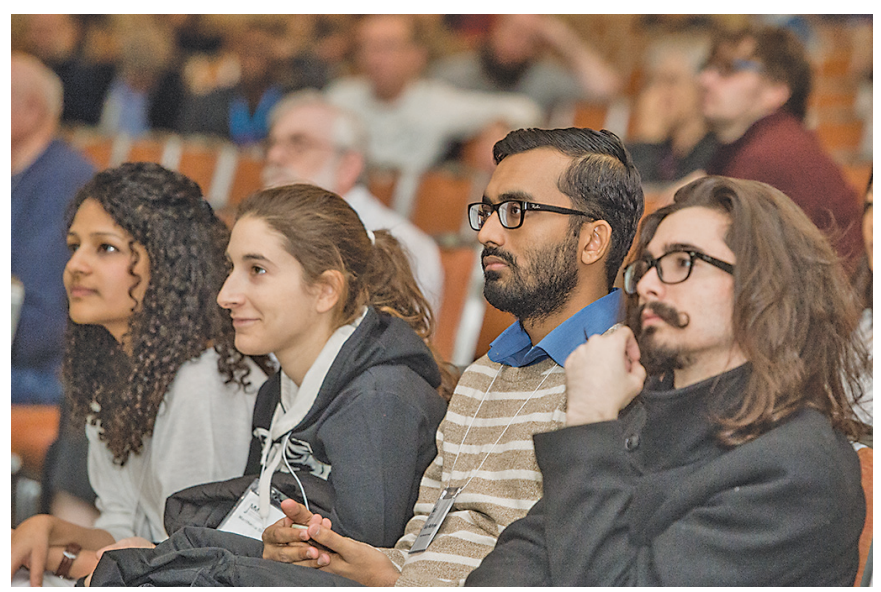

activities that attendees will continue to see these elements in the JMM Reimagined program. Indeed, the AMS welcomes your engagement-please reach out to propose something to help preserve and enhance the January meetings. Societies and math institutes are engaged now with internal discussions about ways in which they might increase or change their involvement with the JMM. What is especially exciting about this level of community engagement is that the importance of the January meetings is abundantly clear. We are extremely grateful to the many suggestions and ideas-you will be hearing from us soon to help realize many of them.

We have assurances from the MAA that the Project NExT activities, the AMS/MAA/SIAM Gerald and Judith Porter lecture, and one MAA/AMS joint invited address will continue. Many of MAA's Special Interest Groups have deep connections with the JMM that they hope to preserve, so if you are part of a Special Interest Group please reach out to the AMS to discuss how we might ensure this. Other MAA activities will be carried on at the JMM. For example, $\mathrm{Pi} \mathrm{Mu}$ Epsilon will run the undergraduate poster sessions and, together with the AMS, will seek funding to continue the undergraduate travel grants that the AMS picked up for JMM 2020. The AMS is already forming plans to continue the rich education and pedagogy content familiar to many who attend the JMM. We will continue something like the MAA mini-courses and introduce new professional development opportunities. Several people have asked if the Graduate Student Fair and the Employment Center will continue-the answer is YES!

If you visit https://www.ams.org/meetings /national/national, you will see that anyone can propose events (all sorts) for future January meetings. Anyone can propose sessions or events of any type, even though we have not yet established a procedure for evaluating and approving proposals. If your group typically holds a business meeting at the JMM, you may schedule those as well. We expect the registration fees to support providing conference rooms with standard $\mathrm{AV}$ to all participating groups for no

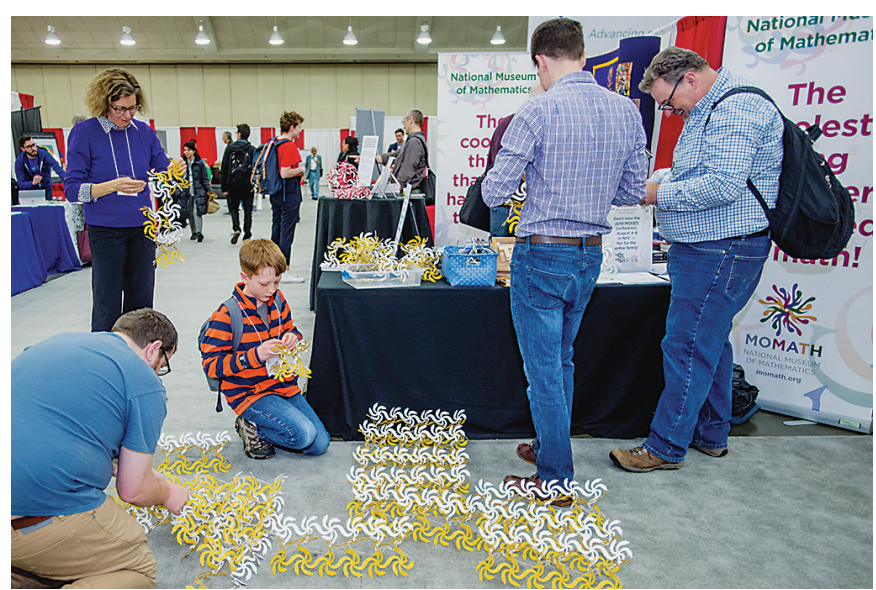

additional charges, but groups will be responsible for catering or "extra" AV. Again, this is a work in progress, and more information will be forthcoming.

The AMS would like to hear from YOU. Please join Executive Director Catherine Roberts and other leaders at a town hall hosted by the AMS Committee on Meetings and Conferences on Friday, January 17, 2020 at our JMM in Denver. Remember, these changes won't go into effect until JMM 2022 in Seattle. Now is the time to help us reimagine the January mathematics meetings!

We both look forward to seeing you in Denver at the Joint Mathematics Meetings. Please enjoy special events in remembrance of Maryam Mirzakhani, including the new AMS Invited Address named in her honor.

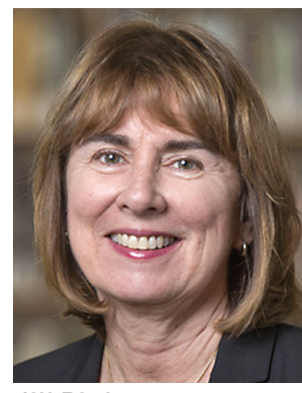

Jill Pipher

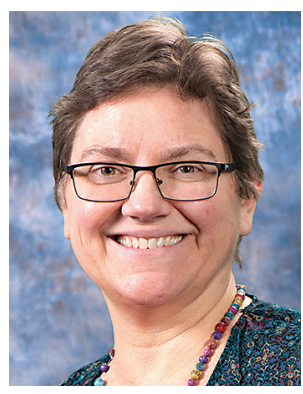

Catherine Roberts

\section{Credits}

Photos from the 2019 JMM are by Kate Awtrey, Atlanta Convention Photography.

Photo of Jill Pipher is courtesy of Brown University. Photo of Catherine Roberts is courtesy of Billy Durvin. 